\title{
An improved model of the distribution and metabolism of progesterone and $20 \alpha$-dihydroprogesterone in sheep
}

\author{
J. Y. F. Paterson, F. A. Harrison, E. L. Sheldrick and R. B. Heap \\ A.R.C. Institute of Animal Physiology, Babraham, Cambridge CB2 4AT, U.K.
}

Summary. When $\left[{ }^{3} \mathrm{H}\right]$ progesterone is infused intravenously into ewes, blood $20 \alpha$ dihydroprogesterone (20 $\alpha$-diHP) becomes labelled and the changes in $\left[{ }^{3} \mathrm{H}\right] 20 \alpha$-diHP activity with time are clearly related to that of $\left[{ }^{3} \mathrm{H}\right]$ progesterone. Concentrations of $20 \alpha$-diHP in blood have now been estimated for these experiments. During the infusion, the specific radioactivity of $20 \alpha$-diHP at steady state was only $53 \%$ of the specific radioactivity of progesterone, indicating that $20 \alpha$-diHP was produced other than by C-20 reduction of secreted progesterone. The change in blood concentration of $20 \alpha$-diHP during pregnancy in ewes suggests that the placenta is its source.

$\left[{ }^{3} \mathrm{H}\right] 20 \alpha$-dihydroprogesterone was infused into pregnant ewes and the specific radioactivity of $20 \alpha$-diHP measured during and after infusion. Together with information from earlier experiments when $\left[{ }^{3} \mathrm{H}\right]$ progesterone was infused, there is now sufficient data to estimate, without constraint, the parameters of a four-pool model describing the distribution and metabolism of progesterone and $20 \alpha$-dyhydroprogesterone in sheep.

\section{Introduction}

Paterson, Bedford, Harrison \& Heap (1976) described the specific radioactivity of progesterone and the concentration of $\left[{ }^{3} \mathrm{H}\right] 20 \alpha$-dihydroprogesterone $(20 \alpha$-diHP) in blood during and after infusion of $\left[7 \alpha^{-3} \mathrm{H}\right]$ progesterone in sheep. On the basis of their observations they proposed a model containing two pools of progesterone and two pools of $20 \alpha$-diHP with irreversible conversion of progesterone to dihydroprogesterone in both pools. The model contained more parameters than could be estimated uniquely from the available experimental information, and constraints were applied to obtain a solution.

We have now estimated the specific radioactivity of $20 \alpha$-diHP during and after infusion of [1,2$\left.{ }^{3} \mathrm{H}\right] 20 \alpha$-dihydroprogesterone in sheep. In these experiments no $\left[{ }^{3} \mathrm{H}\right]$ progesterone could be detected and the earlier assumption that conversion of progesterone to $20 \alpha$-diHP is irreversible is upheld.

We have also estimated blood concentrations of $20 \alpha$-diHP; our earlier assumption that during infusion of $\left[{ }^{3} \mathrm{H}\right]$ progesterone the equilibrium specific radioactivities of progesterone and $20 \alpha$-diHP are equal was not upheld. It was therefore necessary to modify the earlier model to include production of $20 \alpha$-dihydroprogesterone from some source other than progesterone in circulating blood. The additional experimental information provides sufficient degrees of freedom to allow the estimation of the model parameters without imposition of constraints.

\section{Materials and Methods}

\section{Animals and techniques}

Sheep. Clun Forest and Clun Forest $\times$ Merino sheep were used. Details of the animals, their feeding and management have been described previously (Bedford, Harrison \& Heap, 1972). 
Infusion of $20 \alpha$-dihydroprogesterone. $\left[1,2-{ }^{3} \mathrm{H}\right] 20 \alpha$-Hydroxypregn-4-en-3-one (sp. act. $45 \mathrm{Ci} /$ mmol; Radiochemical Centre, Amersham, U.K.) was infused at constant rate of $1 \mu \mathrm{Ci}(7 \mathrm{ng}) / \mathrm{min}$ into a jugular vein for $3.5 \mathrm{~h}$. The sampling procedure was identical to that described by Paterson et al. (1976).

Analysis of blood samples. The amounts of $\left[{ }^{3} \mathrm{H}\right]$ progesterone and of $\left[{ }^{3} \mathrm{H}\right] 20 \alpha$-diHP were measured using the method of Bedford et al. (1972). The concentrations of endogenous progesterone and of $20 \alpha$-diHP in plasma were measured by radioimmunoassay and adjusted to blood concentrations using measured haematocrit. Progesterone was determined by method A of Heap, Gwyn, Laing \& Walters (1973) using the antiserum BF 465 No. 6 (kindly supplied by Dr B. J. A. Furr) which was raised in a goat immunized against progesterone conjugated to bovine serum albumin through the 11-position. The main cross-reactants of the antiserum were progesterone $(100 \%), 11 \alpha$-hydroxypregn-4-ene-3,20-dione $(117 \%)$ and $5 \alpha$-pregnane-3,20-dione $(35 \%)$. In the concentration range 2 to $10 \mathrm{ng} / \mathrm{ml}$ the intra-assay variation was $16.3 \%$ and interassay variation $19.6 \%$.

$20 \alpha$-Dihydroprogesterone was estimated by a procedure similar to that for progesterone, but petroleum ether was replaced by diethyl ether for the extraction of plasma. The antiserum used was P003 (Steranti Research Ltd, St Albans, Herts, U.K.), raised in rabbits against the bovine serum albumin conjugate of $20 \alpha$-diHP 3-(O-carboxymethyl)-oxime. The cross-reactivity of the antiserum with different steroids was determined as the concentration of $20 \alpha$-diHP divided by the concentration of other steroids which caused $50 \%$ displacement expressed as a percentage. The values

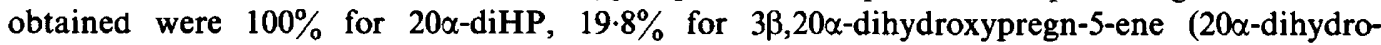
pregnenolone), $8.4 \%$ for progesterone, $1.0 \%$ for pregnanediol, $0.4 \%$ for $20 \beta$-diHP, $0.1 \%$ for $5 \alpha$ dihydroprogesterone, and $<0.1 \%$ for $17 \alpha$-hydroxyprogesterone, pregnanetriol, $16 \alpha$-hydroxyprogesterone, $17 \alpha$-hydroxypregnenolone, $5 \beta$-dihydroprogesterone, deoxycorticosterone, corticosterone, cortisol, pregnenolone, $17 \alpha, 20 \alpha$-dihydroprogesterone, testosterone, 3 $\beta, 5 \beta$-pregnanolone, $3 \alpha, 5 \alpha$-pregnanolone, $3 \beta, 5 \alpha$-pregnanolone and dehydroepiandrosterone (DHA). Over the concentration range 2 to $15.5 \mathrm{ng} / \mathrm{ml}$ the intra-assay variation was $11.1 \%$ and interassay variation was $18 \cdot 1 \%$.

The recoveries of progesterone and $20 \alpha$-diHP from plasma were $78.4 \pm 1 \cdot 1 \%$ and $79 \cdot 6 \pm 3.0 \%$ respectively, and values for concentrations were corrected accordingly. The sensitivities of the assays for progesterone and $20 \alpha$-diHP were 28 and $20 \mathrm{pg} /$ tube respectively (calculated from $2 \times$ s.d. below zero point).

$20 \alpha$-Dihydropregnenolone as a contaminant in $20 \alpha$-diHP assays. Diethyl ether extracts ( $5 \mathrm{ml})$ of 2 $\mathrm{ml}$ plasma were concentrated and applied to a thin-layer chromatograph plate (silica gel $60 \mathrm{~F}-254$, Merck). Using methylene chloride : diethyl ether $(5: 2 \mathrm{v} / \mathrm{v})$ at $4^{\circ} \mathrm{C}$ the chromatogram was run twice over a $17-\mathrm{cm}$ distance. Authentic steroids (Medical Research Council Steroid Reference Collection, Hampstead, London) were run in adjacent lanes on the same t.l.c. place.

Consecutive 2-3 mm bands of the lanes containing plasma extracts were removed, eluted with ethanol, evaporated and their immunoreactivity measured using antiserum P003. Lanes containing authentic steroids were sprayed with glacial acetic acid containing $1 \%$ anisaldehyde and $2 \%$ sulphuric acid and heated briefly at $70^{\circ} \overline{\mathrm{C}}$. The $R_{\mathrm{f}}$ values of $20 \alpha$-diHP and $20 \alpha$-dihydropregnenolone were 0.46 and 0.32 respectively. The $R_{\mathrm{f}}$ values for other steroids tested in the same chromatographic system were $5 \beta$-pregnane- $3 \alpha, 17 \alpha, 20 \alpha$-triol, $<0 \cdot 01 ; 5 \beta$-pregnane-3 $\alpha, 20 \alpha$-diol, $0 \cdot 17 ; \Delta^{4}$-pregnene-

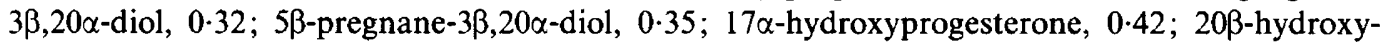
pregn-4-en-3-one, 0.45 ; deoxycorticosterone, 0.48 ; DHA, $0.51 ; 5 \beta$-pregnan-3 $\alpha$-ol-20-one, 0.51 ; $5 \alpha-$

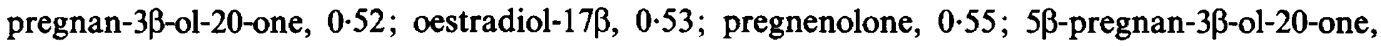
0.59 ; oestradiol- $17 \alpha, 0.62$; progesterone, $0.72 ; 5 \beta$-pregnane-3,20-dione, $0.85 ; 5 \alpha$-pregnane-3,20dione, $0 \cdot 87$.

\section{Mathematical methods}

The model is shown in Text-fig. 1: $\mathrm{Q}_{1}$ and $\mathrm{Q}_{2}$ are the two pools of progesterone and $\mathrm{Q}_{4}$ and $\mathrm{Q}_{3}$ the pools of $20 \alpha$-diHP; $Q_{1}$ defines pool size $(\mu \mathrm{g})$ and $\alpha_{\mathrm{i}}$ its specific radioactivity $(\mu \mathrm{Ci} / \mu \mathrm{g}) ; \mathrm{s}_{1}$ is the 


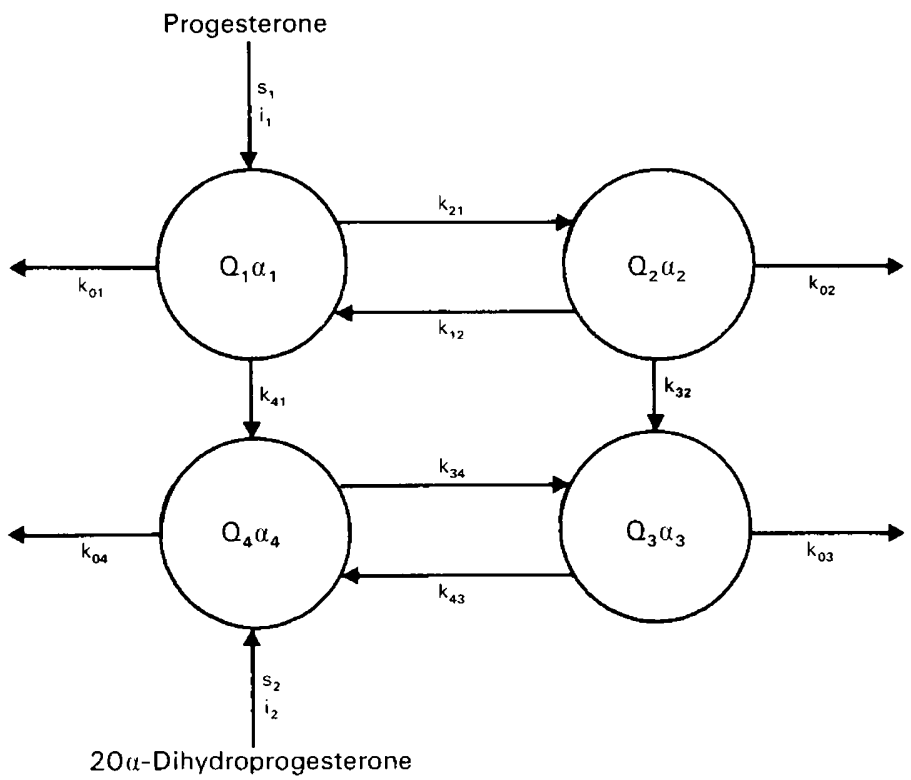

Text-fig. 1. A four-pool model of progesterone and $20 \alpha$-dihydroprogesterone (20 $\alpha$-diHP) distribution and metabolism in sheep. $Q_{1}$ and $Q_{2}$ are the two pools of progesterone and $Q_{4}$ and

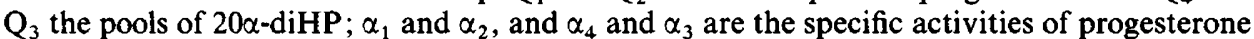
and $20 \alpha$-diHP, respectively; $s_{1}$ is the secretion rate of progesterone and $s_{2}$ the rate of production of $20 \alpha$-diHP from sources other than secreted progesterone. The proportion of $Q_{i}$ transferred per unit time to $Q_{j}$ is represented by the rate constant $\mathbf{k}_{\mathrm{ji}}$.

secretion rate of progesterone and $s_{2}$ the rate of production of $20 \alpha$-diHP from sources other than secreted progesterone. Later $i_{1}$ and $i_{2}$ will be used to represent rates of infusion of $\left[{ }^{3} \mathrm{H}\right]$ progesterone and $\left[{ }^{3} \mathrm{H}\right] 20 \alpha$-dihydroprogesterone, respectively.

The proportion of $Q_{i}$ transferred per unit time to $Q_{j}$ is represented by the rate constant $k_{j i}$. The sum of all rate constants for $Q_{i}$ is $k_{i i}$. The rate of change of $Q_{i}, d Q_{i} / d t$, is represented by $Q_{i}^{\prime}$ and the model is then described by the set of linear differential equations.

$$
\begin{aligned}
& Q_{1}^{\prime}=s_{1}-k_{11} Q_{1}+k_{12} Q_{2} \\
& Q_{2}{ }^{\prime}=k_{21} Q_{1}-k_{22} Q_{2} \\
& Q_{3}{ }^{\prime}= \\
& \mathrm{k}_{32} Q_{2}-k_{33} Q_{3}+k_{34} Q_{4} \\
& Q^{\prime}=s_{2}+k_{41} Q_{1} \quad+k_{43} Q_{3}-k_{44} Q_{4}
\end{aligned}
$$

These equations can be solved readily by Laplace transformation, and in the steady state the pool sizes are

$$
\begin{aligned}
& \mathrm{Q}_{1}=\mathrm{k}_{22} \mathrm{~s}_{1} / \lambda_{1} \lambda_{2} \\
& \mathrm{Q}_{2}=\mathrm{k}_{21} \mathrm{~s}_{1} / \lambda_{1} \lambda_{2} \\
& \mathrm{Q}_{3}=\left(\left[\mathrm{k}_{44} \mathrm{k}_{32} \mathrm{k}_{21}+\mathrm{k}_{41} \mathrm{k}_{34} \mathrm{k}_{22}\right] \mathrm{s}_{1}+\left[\lambda_{1} \lambda_{2} \mathrm{k}_{34}\right] \mathrm{s}_{2}\right) / \lambda_{1} \lambda_{2} \lambda_{3} \lambda_{4} \\
& \mathrm{Q}_{4}=\left(\left[\mathrm{k}_{43} \mathrm{k}_{32} \mathrm{k}_{21}+\mathrm{k}_{41} \mathrm{k}_{33} \mathrm{k}_{22}\right] \mathrm{s}_{1}+\left[\lambda_{1} \lambda_{2} \mathrm{k}_{33}\right] \mathrm{s}_{2}\right) / \lambda_{1} \lambda_{2} \lambda_{3} \lambda_{4}
\end{aligned}
$$

where

$$
\begin{aligned}
& \lambda_{1}, \lambda_{2}=\left(k_{11}+k_{22} \pm\left[\left(k_{11}+k_{22}\right)^{2}-4\left(k_{11} k_{22}-k_{21} k_{12}\right)\right]^{\frac{1}{2}}\right) / 2 \\
& \lambda_{3}, \lambda_{4}=\left(k_{33}+k_{44} \pm\left[\left(k_{33}+k_{44}\right)^{2}-4\left(k_{33} k_{44}-k_{43} k_{34}\right)\right]^{\frac{1}{2}}\right) / 2
\end{aligned}
$$


The differential equations can also be written in terms of specific radioactivities during and after infusion of labelled progesterone $\left(i_{1}\right)$ or $20 \alpha$-dihydroprogesterone $\left(i_{2}\right)$. The solutions for the accessible pools of progesterone $\left(\mathrm{Q}_{1}\right)$ and $20 \alpha$-diHP $\left(\mathrm{Q}_{4}\right)$ are as follows.

Infusion of $\left[{ }^{3} \mathrm{H}\right]$ progesterone

$$
\begin{aligned}
\alpha_{1}(t)= & \frac{i_{1}}{s_{1}}\left\{1-\frac{\lambda_{2}\left(k_{22}-\lambda_{1}\right)}{k_{22}\left(\lambda_{2}-\lambda_{1}\right)} e^{-\lambda_{1} t}-\frac{\lambda_{1}\left(k_{22}-\lambda_{2}\right)}{k_{22}\left(\lambda_{1}-\lambda_{2}\right)} e^{-\lambda_{2} t}\right\} \\
\alpha_{4}(t)= & \frac{\left(k_{43} k_{32} k_{21}+k_{41} k_{22} k_{33}\right) i_{1}}{\left(k_{43} k_{32} k_{21}+k_{41} k_{22} k_{33}\right) s_{1}+\left(\lambda_{1} \lambda_{2} k_{33}\right) s_{2}}\{1- \\
& \frac{\lambda_{2} \lambda_{3} \lambda_{4}\left(k_{41}\left(k_{22}-\lambda_{1}\right)\left(k_{33}-\lambda_{1}\right)+k_{43} k_{32} k_{21}\right) e^{-\lambda_{1} t}}{\left(k_{43} k_{32} k_{21}+k_{41} k_{22} k_{33}\right)\left(\lambda_{2}-\lambda_{1}\right)\left(\lambda_{3}-\lambda_{1}\right)\left(\lambda_{4}-\lambda_{1}\right)} \\
- & \frac{\lambda_{1} \lambda_{3} \lambda_{4}\left(k_{41}\left(k_{22}-\lambda_{2}\right)\left(k_{33}-\lambda_{2}\right)+k_{43} k_{32} k_{21}\right) e^{-\lambda_{2} t}}{\left(k_{43} k_{32} k_{21}+k_{41} k_{22} k_{33}\right)\left(\lambda_{1}-\lambda_{2}\right)\left(\lambda_{3}-\lambda_{2}\right)\left(\lambda_{4}-\lambda_{2}\right)} \\
- & \frac{\lambda_{1} \lambda_{2} \lambda_{4}\left(k_{41}\left(k_{22}-\lambda_{3}\right)\left(k_{33}-\lambda_{3}\right)+k_{43} k_{32} k_{21}\right) e^{-\lambda_{3} t}}{\left(k_{43} k_{32} k_{21}+k_{41} k_{22} k_{33}\right)\left(\lambda_{1}-\lambda_{3}\right)\left(\lambda_{2}-\lambda_{3}\right)\left(\lambda_{4}-\lambda_{3}\right)} \\
- & \left.\frac{\lambda_{1} \lambda_{2} \lambda_{3}\left(k_{41}\left(k_{22}-\lambda_{4}\right)\left(k_{33}-\lambda_{4}\right)+k_{43} k_{32} k_{21}\right) e^{-\lambda_{4} t}}{\left(k_{43} k_{32} k_{21}+k_{41} k_{22} k_{33}\right)\left(\lambda_{1}-\lambda_{4}\right)\left(\lambda_{2}-\lambda_{4}\right)\left(\lambda_{3}-\lambda_{4}\right)}\right\}
\end{aligned}
$$

Infusion of $\left[{ }^{3} \mathrm{H}\right] 20 \alpha$-dihydroprogesterone

$$
\begin{aligned}
\alpha_{4}(t)= & \frac{\lambda_{1} \lambda_{2} k_{33} i_{2}}{\left(k_{43} k_{32} k_{21}+k_{41} k_{22} k_{33}\right) s_{1}+\left(\lambda_{1} \lambda_{2} k_{33}\right) s_{2}} \\
& \left.\frac{\lambda_{4}\left(k_{33}-\lambda_{3}\right)}{k_{33}\left(\lambda_{4}-\lambda_{3}\right)} e^{-\lambda_{3} t}-\frac{\lambda_{3}\left(k_{33}-\lambda_{4}\right)}{k_{33}\left(\lambda_{3}-\lambda_{4}\right)} e^{-\lambda_{4} t}\right)
\end{aligned}
$$

When equilibrium specific radioactivity has been attained and the infusion is then discontinued, the appropriate function is equilibrium specific activity minus the expression shown above, but with $t^{\prime}$, time after the ending of infusion.

Estimation of model parameters. There are 12 parameters to be estimated, the 10 rate constants $\mathrm{k}_{01}-\mathrm{k}_{34}$ and the 2 entry rates $s_{1}$ and $s_{2}$. These were used to derive, iteratively, the exponential coefficients and constants for $\alpha_{1}$ and $\alpha_{4}$ shown above. From these, and the experimental values of (t) and $\left(t^{\prime}\right)$, the predicted values of specific activity $\hat{\alpha}_{1 \mathrm{j}}$ and $\hat{\alpha}_{4 \mathrm{j}}$ were obtained. The experimentally measured specific activities were lognormally distributed, and so the sum of squares to be minimized was

$$
S=\sum_{j=1}^{j=N}\left[\ln \left(\alpha_{j} / \hat{\alpha}_{j}\right)\right]^{2}
$$

The subroutines EO4HBF and EO4JBF from the Mk 7 NAG library (Numerical Algorithms Group, Banbury Road, Oxford) were used for the minimization procedure. The initial values for the parameters were taken from Paterson et al. (1976).

\section{Results}

\section{Plasma concentrations of endogenous $20 \alpha$-diHP and progesterone}

The immunoreactivity of plasma extracts after thin-layer chromatography and elution of consecutive strips of silica gel is shown in Text-fig. 2. The immunoreactivity measured by 


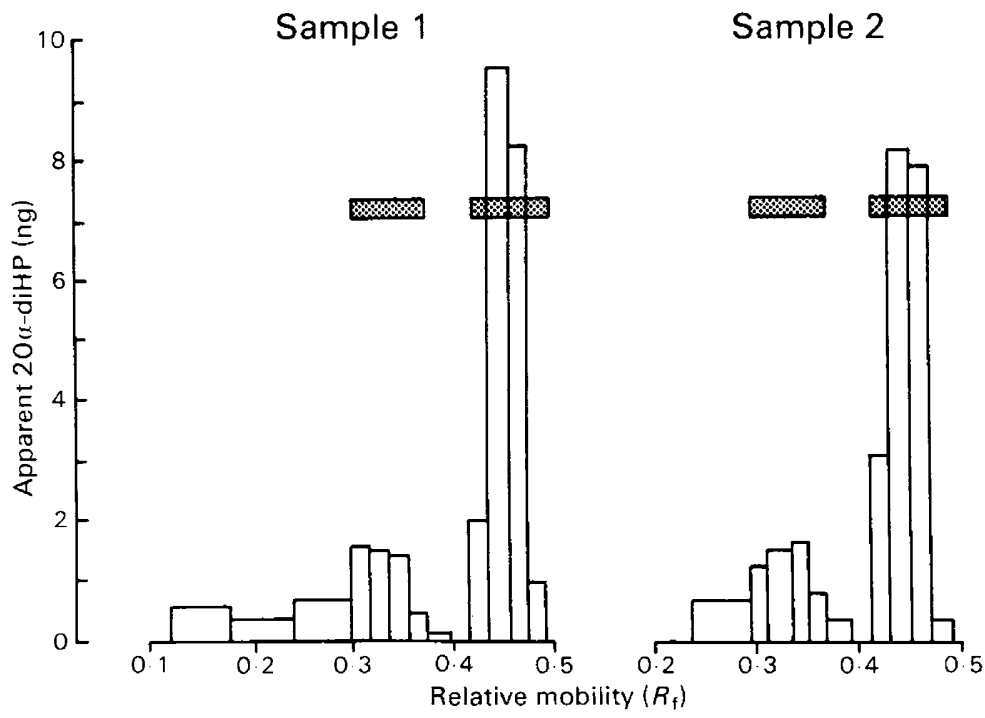

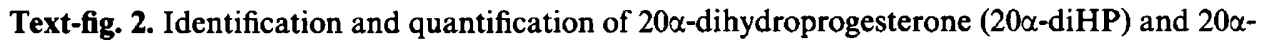
dihydropregnenolone in plasma extracts by thin-layer chromatography on silica gel, elution and reaction with 20 $\alpha$-dihydroprogesterone antiserum P003. Sample 1 is from sheep C355 at 134 days p.c. and Sample 2 from sheep F286 at 112 days p.c. The hatched bars indicate the

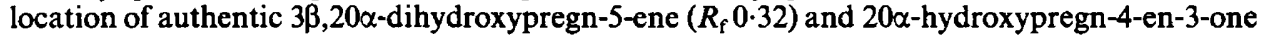
$\left(R_{\mathrm{f}} 0 \cdot 46\right)$; progesterone has an $R_{\mathrm{f}}$ of 0.72 .

antiserum P003 was mainly associated with two bands, chromatographically identical with authentic $20 \alpha$-dihydroprogesterone and $20 \alpha$-dihydropregnenolone.

Nine plasma samples from 4 sheep were examined in this way and there was a highly significant correlation ( $r=0.984,7$ d.f.) between the concentrations of $20 \alpha$-diHP ( $x ; 5.6$ to $34.2 \mathrm{ng}$ ) and $20 \alpha$-dihydropregnenolone $(y ; 7 \cdot 8$ to $47.5 \mathrm{ng})$. The regression equation was $y=2 \cdot 1( \pm 2 \cdot 3)+1 \cdot 39$ $( \pm 0.09) x$. Since the intercept was not significantly different from zero, the slope was calculated through the origin (1.466 \pm 0.037$)$. Plasma extracts of $20 \alpha$-diHP, not purified by t.l.c., therefore contain $100 / 1.68=60 \% 20 \alpha$-dihydropregnenolone. The cross-reactivity of $20 \alpha$-dihydropregnenolone with $\mathrm{P} 003$ antiserum is only $20 \%$ that of $20 \alpha$-diHP and the immunoreactivity of such unpurified extracts is $(0.4 \times 1.0+0.6 \times 0.2) /(0.4 \times 1.0)=1.3$ times that for the true content of 20di-HP.

Progesterone and $20 \alpha$-dihydroprogesterone concentrations were measured in 43 plasma samples from non-pregnant (oestrous cycle) and pregnant ewes. The progesterone concentration was $2.3 \pm 0.7 \mathrm{ng} / \mathrm{ml}$ in non-pregnant ewes and it increased in pregnancy to $2.4 \pm 0.7 \mathrm{ng} / \mathrm{ml}$ (Days $1-50$ ), $13 \cdot 1 \pm 1 \cdot 7 \mathrm{ng} / \mathrm{ml}$ (Days 51-100), $8 \cdot 3 \pm 1 \cdot 5 \mathrm{ng} / \mathrm{ml}$ (Days 101-125) and $7 \cdot 1 \mathrm{ng} / \mathrm{ml}$ (Day 126 to term). The $20 \alpha$-diHP concentration (corrected) was $1.9 \pm 0.2 \mathrm{ng} / \mathrm{ml}$ in non-pregnant animals and $2 \cdot 8 \pm 0 \cdot 2,10 \cdot 1 \pm 1 \cdot 3,14 \cdot 6 \pm 2 \cdot 3$ and $11 \cdot 6 \pm 1 \cdot 4 \mathrm{ng} / \mathrm{ml}$ in pregnancy (Days $1-50,51-100,101-125$, 126-term, respectively).

Specific activity of $20 \alpha$-diHP during and after infusion of $\left[1,2-{ }^{3} H\right] 20 \alpha$-dihydroprogesterone

$\left[{ }^{3} \mathrm{H}\right] 20 \alpha$-dihydroprogesterone was infused into a jugular vein in 6 experiments on 5 pregnant ewes between Days 117 and 138 post coitum. Arterial blood concentrations of $20 \alpha-\mathrm{diHP}$ and progesterone are shown in Table 1 together with the fitted time curves for $\left[{ }^{3} \mathrm{H}\right] 20 \alpha$-diHP concentrations during and after the infusion. Since the between-experiment differences in blood $\left[{ }^{3} \mathrm{H}\right] 20 \alpha-$ 
Table 1. Arterial blood concentrations of progesterone and $20 \alpha$-dihydroprogesterone

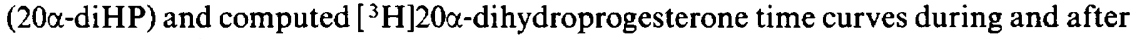
infusion of $\left[{ }^{3} \mathrm{H}\right] 20 \alpha$-dihydroprogesterone, standardized to an infusion rate of $1 \mu \mathrm{Ci} / \mathrm{min}$

\begin{tabular}{|c|c|c|c|c|c|c|c|c|}
\hline \multirow[b]{2}{*}{ Sheep } & \multirow[b]{2}{*}{$\begin{array}{c}\text { Days } \\
\text { pregnant }\end{array}$} & \multirow[b]{2}{*}{$\begin{array}{c}20 \alpha \text {-diHP } \\
(\mathrm{ng} / \mathrm{ml})\end{array}$} & \multirow[b]{2}{*}{$\begin{array}{l}\text { Progesterone } \\
(\mathrm{ng} / \mathrm{ml})\end{array}$} & \multicolumn{5}{|c|}{$\left[{ }^{3} \mathrm{H}\right] 20 \alpha-\mathrm{diH} \mathrm{P}^{*}$} \\
\hline & & & & $\begin{array}{c}E \\
(\mu \mathrm{Ci} / 1)\end{array}$ & A & B & $\begin{array}{c}\alpha \\
\left(\min ^{-1}\right)\end{array}$ & $\begin{array}{c}\beta \\
\left(\min ^{-1}\right)\end{array}$ \\
\hline Rennet & 117 & $7 \cdot 7$ & $2 \cdot 8$ & 0.329 & 0.619 & $0 \cdot 381$ & 0.534 & 0.0382 \\
\hline Rennet & 138 & $6 \cdot 1$ & 3.8 & $0 \cdot 350$ & 0.542 & 0.458 & 1.006 & 0.0148 \\
\hline Whim & 120 & $3 \cdot 4$ & $4 \cdot 5$ & 0.386 & 0.563 & 0.437 & 0.370 & 0.0142 \\
\hline Warble & 120 & $5 \cdot 5$ & $8 \cdot 1$ & $0 \cdot 492$ & 0.683 & 0.317 & 0.800 & 0.0221 \\
\hline Witch & 138 & $2 \cdot 8$ & $5 \cdot 0$ & 0.387 & 0.690 & 0.310 & 0.708 & 0.0259 \\
\hline Treacle & 136 & 3.9 & $2 \cdot 6$ & 0.367 & 0.746 & 0.254 & 2.074 & $0 \cdot 0167$ \\
\hline Pooled & & 4.9 & $4 \cdot 5$ & 0.380 & 0.640 & $0 \cdot 360$ & 0.785 & 0.0206 \\
\hline
\end{tabular}

$\mathrm{E}=$ equilibrium tracer concentration; $\mathrm{A}, \mathrm{B}=$ fractional constants $(\mathrm{A}+\mathrm{B}=1) ; \alpha, \beta=$ exponential coefficients.

* The exponential function fitted to blood $\left[{ }^{3} \mathrm{H}\right] 20 \alpha$-diHP is of the form:

and

$$
\begin{aligned}
{\left[{ }^{3} \mathrm{H}\right] 20 \alpha-\mathrm{diHP} } & =\mathrm{E}\left(1-\mathrm{A} \mathrm{e}^{-\alpha t}-\mathrm{B} \mathrm{e}^{-\beta \mathrm{t}}\right) \mu \mathrm{Ci} / \mathrm{l} \text { during infusion, } \\
& =\left(\mathrm{A}^{-\alpha t}+\mathrm{B} \mathrm{e}^{-\beta \mathrm{t}}\right) \mu \mathrm{Ci} / 1 \text { after infusion. }
\end{aligned}
$$

diHP and $\left[{ }^{3} \mathrm{H}\right]$ progesterone concentrations appeared to be random, the standardized values, calculated as described by Paterson et al. (1976), were pooled (Table 2).

Table 2. Whole blood concentrations of $\left[{ }^{3} \mathrm{H}\right]$ progesterone and $\left[{ }^{3} \mathrm{H}\right] 20 \alpha-$ dihydroprogesterone (20 $\alpha$-diHP) during and after infusions of labelled

\begin{tabular}{|c|c|c|c|c|}
\hline \multicolumn{3}{|c|}{$\left[{ }^{3} \mathrm{H}\right]$ progesterone $(1 \mu \mathrm{Ci} / \mathrm{min})$} & \multirow{2}{*}{\multicolumn{2}{|c|}{$\left[{ }^{3} \mathrm{H}\right] 20 \alpha-\operatorname{diHP}(1 \mu \mathrm{Ci} / \mathrm{min})$}} \\
\hline \multirow[b]{2}{*}{$\begin{array}{l}\text { Time } \\
\text { (min) }\end{array}$} & \multicolumn{2}{|c|}{ Mean \pm s.e.m. conc. $(\mu \mathrm{Ci} / 1)$} & & \\
\hline & Progesterone & $20 \alpha-$ diHP & $\begin{array}{l}\text { Time } \\
\text { (min) }\end{array}$ & $\begin{array}{l}20 \alpha-\mathrm{diHP} \\
\text { conc. }(\mu \mathrm{Ci} / 1)\end{array}$ \\
\hline 145 & $0.302 \pm 0.0138$ & $0.158 \pm 0.0114$ & 175 & $0.387 \pm 0.0219$ \\
\hline 175 & $0.316 \pm 0.0179$ & $0.175 \pm 0.0243$ & 205 & $0.382 \pm 0.0198$ \\
\hline 205 & $0.302 \pm 0.0145$ & $0.154 \pm 0.0128$ & 235 & $0.387 \pm 0.0317$ \\
\hline \multicolumn{3}{|c|}{ (210 infusion stopped) } & \multicolumn{2}{|c|}{ (240 infusion stopped) } \\
\hline 0.5 & $0.243 \pm 0.0170$ & $0.161 \pm 0.0199$ & 1 & $0.242 \pm 0.0336$ \\
\hline 1 & $0.200 \pm 0.0166$ & $0.157 \pm 0.0170$ & 2 & $0.179 \pm 0.0234$ \\
\hline 2 & $0.157 \pm 0.0107$ & $0.141 \pm 0.0128$ & 3 & $0.160 \pm 0.0192$ \\
\hline 3 & $0.127 \pm 0.0094$ & $0.135 \pm 0.0127$ & 4 & $0.147 \pm 0.0151$ \\
\hline 4 & $0.110 \pm 0.0071$ & $0.125 \pm 0.0110$ & 5 & $0.149 \pm 0.0161$ \\
\hline 5 & $0.092 \pm 0.0057$ & $0.120 \pm 0.0103$ & 10 & $0.117 \pm 0.0233$ \\
\hline 15 & $0.053 \pm 0.0050$ & $0.099 \pm 0.0147$ & 15 & $0.089 \pm 0.0113$ \\
\hline 30 & $0.035 \pm 0.0037$ & $0.077 \pm 0.0150$ & 30 & $0.069 \pm 0.0101$ \\
\hline 45 & $0.029 \pm 0.0040$ & $0.055 \pm 0.0101$ & 45 & $0.057 \pm 0.0104$ \\
\hline 60 & $0.023 \pm 0.0034$ & $0.042 \pm 0.0097$ & 60 & $0.050 \pm 0.0090$ \\
\hline
\end{tabular}
progesterone and $20 \alpha$-diHP

The concentrations for $\left[{ }^{3} \mathrm{H}\right]$ progesterone infusion are taken from Paterson et al. (1976) with $n=23$. The concentrations for $\left[{ }^{3} \mathrm{H}\right] 20 \alpha$-diHP infusion are for the 6 experiments described in this paper. 
The specific radioactivities of progesterone and $20 \alpha$-diHP for infusion rates of $1 \mu \mathrm{Ci} / \mathrm{min}$, are shown in Text-fig. 3 together with the functions fitted in parameter estimation, which were
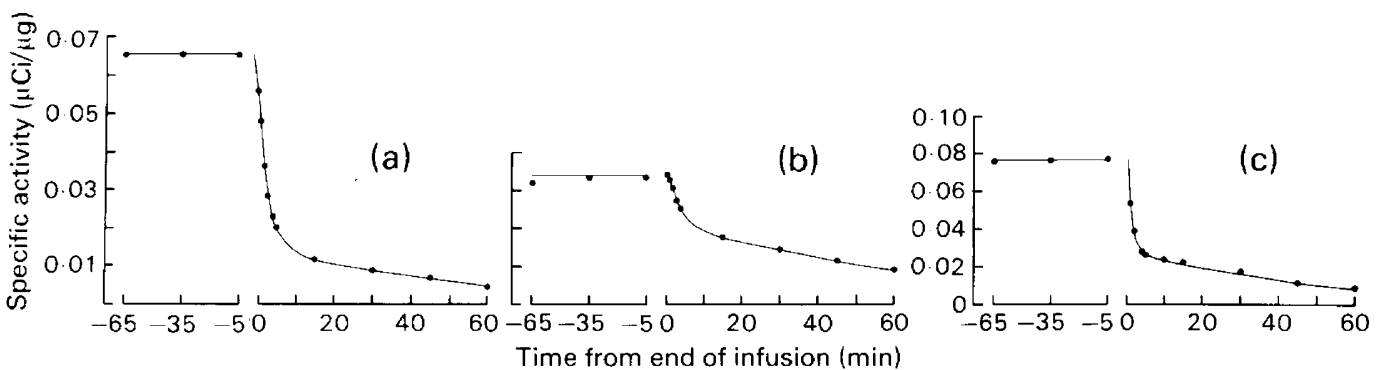

Text-fig. 3. Measured blood specific activities of (a) $\left[{ }^{3} \mathrm{H}\right]$ progesterone and (b) $\left[{ }^{3} \mathrm{H}\right] 20 \alpha-$

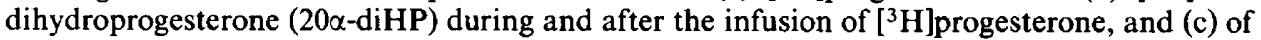
$\left[{ }^{3} \mathrm{H}\right] 20 \alpha$-diHP during and after the infusion of $\left[{ }^{3} \mathrm{H}\right] 20 \alpha$-diHP in pregnant sheep. The computed lines for the blood concentrations are given.

(a) $\left[{ }^{3} \mathrm{H}\right]$ Prog $=0.0660\left(1.0-0.7593 \mathrm{e}^{-0.4373 t}-0.2407 \mathrm{e}^{-0.0202 t}\right) \mu \mathrm{Ci} / \mu \mathrm{g}$

(b) $\left[{ }^{3} \mathrm{H}\right] 20 \alpha=0.0348\left(1.0-0.9906 \mathrm{e}^{-0.4373 \mathrm{t}}+5.9402 \mathrm{e}^{-0.2020 \mathrm{t}}+0.5995 \mathrm{e}^{-0.7346 \mathrm{t}}-\right.$ $\left.6.5491 \mathrm{e}^{-0.0194 t}\right) \mu \mathrm{Ci} / \mu \mathrm{g}$

(c) $\left[{ }^{3} \mathrm{H}\right] 20 \alpha=0.0774\left(1.0-0.6328 \mathrm{e}^{-0.7346 \mathrm{t}}-0.3672 \mathrm{e}^{-0.0194 \mathrm{t}}\right) \mu \mathrm{Ci} / \mu \mathrm{g}$

Equations (a) and (b) refer to the infusion of $\left[{ }^{3} \mathrm{H}\right]$ progesterone and (c) to the infusion of $\left[{ }^{3} \mathrm{H}\right] 20 \alpha$ dihydroprogesterone.

The estimate of the parameters and their standard errors of estimate are given in Table 3, and the pool sizes and fluxes for the two steroids derived from these parameters are shown in Text-fig. 4.

Table 3. Parameters and standard errors of estimate for the distribution and metabolism of progesterone and $20 \alpha$-dihydroprogesterone

Paterson et al. (1976)

\begin{tabular}{|c|c|c|}
\hline $\mathbf{k}_{01}$ & $0.1214 \pm 0.0129 \mathrm{~min}^{-1}$ & $0 \cdot 1228 \mathrm{~min}^{-1}$ \\
\hline$k_{21}$ & $0.1823 \pm 0.0248 \mathrm{~min}^{-1}$ & $0.3783 \mathrm{~min}^{-1}$ \\
\hline $\mathbf{k}_{41}$ & $0.1276 \pm 0.0161 \mathrm{~min}^{-1}$ & $0.0823 \mathrm{~min}^{-1}$ \\
\hline $\mathbf{k}_{02}$ & $0.00797 \pm 0.00059 \mathrm{~min}^{-1}$ & $0.0110 \mathrm{~min}^{-1}$ \\
\hline $\mathbf{k}_{12}$ & $0.01365 \pm 0.00288 \mathrm{~min}^{-1}$ & $0.0185 \mathrm{~min}^{-1}$ \\
\hline $\mathbf{k}_{32}$ & $0.00466 \pm 0.00102 \mathrm{~min}^{-1}$ & $0.0124 \mathrm{~min}^{-1}$ \\
\hline $\mathbf{k}_{03}$ & $0.0081 \pm 0.00053 \mathrm{~min}^{-1}$ & $0.0263 \mathrm{~min}^{-1}$ \\
\hline $\mathbf{k}_{\mathbf{4 3}}$ & $0.0221 \pm 0.0037 \mathrm{~min}^{-1}$ & $0.0185 \mathrm{~min}^{-1}$ \\
\hline $\mathbf{k}_{04}$ & $0.3801 \pm 0.0672 \mathrm{~min}^{-1}$ & $0 \cdot 1288 \mathrm{~min}^{-1}$ \\
\hline $\mathrm{k}_{34}$ & $0.3437 \pm 0.0731 \mathrm{~min}^{-1}$ & $0 \cdot 1938 \mathrm{~min}^{-1}$ \\
\hline$s_{1}$ & $15.15 \pm 0.60 \mu \mathrm{g} / \mathrm{min}$ (progesterone) & $18.3 \mu \mathrm{g} / \mathrm{min}$ \\
\hline $\mathrm{s}_{2}$ & $6.11 \pm 0.45 \mu \mathrm{g} / \mathrm{min}(20 \alpha-\mathrm{diHP})$ & 0 \\
\hline
\end{tabular}




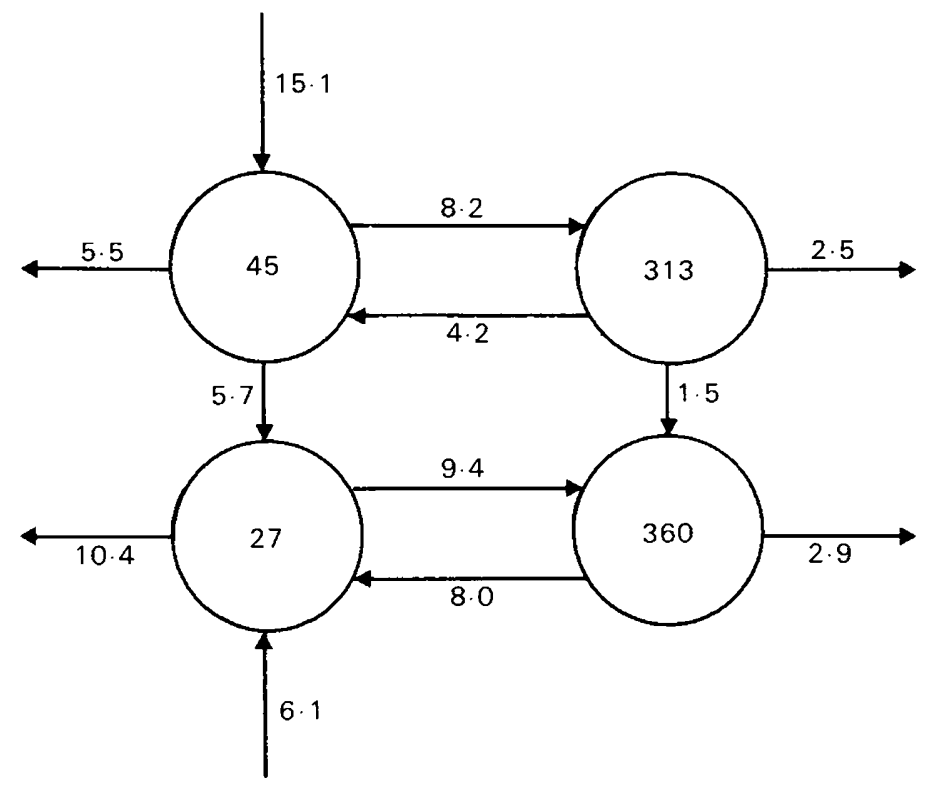

Text-fig. 4. Computed parameters of the four-pool model of progesterone and 20 $\alpha$-dihydroprogesterone distribution and metabolism in pregnant sheep. The values for pool size $(\mu \mathrm{g})$ and for fluxes $(\mu \mathrm{g} / \mathrm{min})$ correspond to the parameters described in Text-fig. 1 and in the text.

The MCR of $20 \alpha$-diHP ( $s_{2} \mu \mathrm{g} / \mathrm{min} /$ arterial blood concentration, $\mu \mathrm{g} / \mathrm{l}$ ) was $1.241 / \mathrm{min}$ compared with that of $3.36 \mathrm{l} / \mathrm{min}$ for progesterone.

\section{Discussion}

Bedford et al. (1972) observed a close correlation between the equilibrium concentrations in blood of $\left[{ }^{3} \mathrm{H}\right]$ progesterone and $\left[{ }^{3} \mathrm{H}\right] 20 \alpha$-dihydroprogesterone during infusion of $\left[{ }^{3} \mathrm{H}\right]$ progesterone. The slope of the regression line was indistinguishable from that observed by Short \& Moore (1959) for

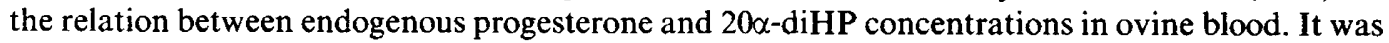
on this basis that we had earlier assumed that the $20 \alpha$-dihydroprogesterone arose solely by reduction of secreted progesterone, and consequently the specific radioactivities of the two steroids were equal. We have now estimated the blood concentrations of $20 \alpha$-hydroxypregn-4-en-3-one and have found that, relative to progesterone, they were greater than expected. During infusion of $\left[{ }^{3} \mathrm{H}\right]-$ progesterone the equilibrium specific activity of $\left[{ }^{3} \mathrm{H}\right] 20 \alpha-\mathrm{diHP}$ is $53 \%$ that of progesterone and it is clear that there must be a source of $20 \alpha$-diHP other than C-20 reduction of circulating progesterone. The results of the present study show that the metabolic clearance rate of $20 \alpha$-diHP is $1.241 / \mathrm{min}$ compared with an estimated value of $3.36 \mathrm{l} / \mathrm{min}$ for progesterone, the latter value being similar to that reported previously (3.64 1/min: Bedford et al., 1972).

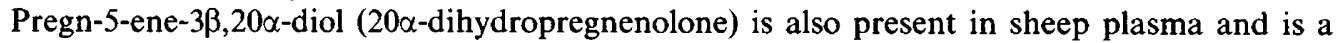
contaminant in our 20 $\alpha$-diHP assay. Due allowance was made for this contamination and the concentrations of 20 $\alpha$-diHP in blood samples taken from Day 126 to term are similar to those reported by Short \& Moore (1959) who used chromatographic separation and u.v. spectrophotometry, and by Elsner et al. (1980) who used a celite chromatographic separation and two radioimmunoassays with different antisera. Progesterone concentrations measured in our study were identical with those found by Short \& Moore (1959) but at the lower end of the range of values recorded by Elsner 
et al. (1980). In the present study the concentrations of $20 \alpha$-dihydroprogesterone and $20 \alpha$-dihydropregnenolone were closely correlated and it would appear likely that they originate from the same source.

Our observations refer mainly to late pregnancy in ewes (120 days p.c. or more) when placental secretion of progesterone is dominant. Ainsworth \& Ryan (1967) showed that the ovine placenta in vitro could produce progesterone from pregnenolone, and also that it could metabolize progesterone to a variety of $20 \alpha, 20 \beta$ and ring A reduction products. Pierrepoint, Anderson, Turnbull \& Griffiths (1973), in similar studies, have confirmed and extended these observations. Our observation that the blood concentration of $20 \alpha$-diHP increases after Day 50 of pregnancy suggests that its source is the placenta since this is the time when placental secretion of progesterone becomes substantial (Ricketts \& Flint, 1980) and that this is also the source of $20 \alpha$-dihydropregnenolone. The blood concentrations of this latter steroid are greater than those of $20 \alpha$-diHP and it is therefore surprising that it has not been reported as a metabolite of pregnenolone or progesterone in in-vitro studies. It may be that in the whole animal the $20 \alpha$-dihydropregnenolone is secreted into blood flowing through the uterus, whereas when chopped placentomes are used the steroid is more readily exposed to enzyme systems which reduce it further.

The assumption by Paterson et al. (1976) that progesterone was the sole source of $20 \alpha$-dihydroprogesterone was extended to the assumption that both steroids occupied the same volumes of distribution. From the observations of Bedford et al. (1974) it was assumed that $30 \%$ of the metabolism of each steroid could be accounted for by irreversible splanchnic extraction as represented by $\mathrm{k}_{01}$ and $\mathrm{k}_{04}$ (see Text-fig. 1). By the use of such constraints Paterson et al. (1976) were able to estimate values for the remaining parameters in the model. The observations described in the present paper have necessitated the inclusion in the model of a source of $20 \alpha$-dihydroprogesterone other than $\mathrm{C}-20$ reduction of secreted progesterone. At the same time, the observations on $20 \alpha$-diHP specific activity during and after infusion of $\left[{ }^{3} \mathrm{H}\right] 20 \alpha$-dihydroprogesterone provide sufficient extra degrees of freedom to enable us to determine the model parameters without making any assumptions or constraints.

During the infusion of $\left[{ }^{3} \mathrm{H}\right] 20 \alpha$-dihydroprogesterone there was no observable ${ }^{3} \mathrm{H}$-labelling of progesterone, indicating that the reduction at $\mathrm{C}-20$ is irreversible, which had been a tentative conclusion of Paterson et al. (1976). It follows that the changes resulting from application of the unconstrained estimation of parameters reported here must be confined largely to the $20 \alpha$-diHP pools in the model. Paterson et al. (1976) had assumed that $30 \%$ of secreted progesterone was removed by splanchnic extraction (as represented by $\mathrm{k}_{01}$ ) and this is the value estimated in the present paper. In the model of Paterson et al. (1976) $46 \%$ of progesterone was converted to $20 \alpha$-diHP, and in the present work we calculate that there is $53 \% \mathrm{C}-20$ reduction of progesterone to $20 \alpha$-diHP, predominantly from the smaller pool of progesterone.

The endogenous production of $20 \alpha$-dihydroprogesterone represented as $s_{2}$ in the model (Textfig. 1) is $40 \%$ of the secretion rate for progesterone (Text-fig. 4). This results in pool sizes for $20 \alpha-$ diHP similar to those estimated by Paterson et al. (1976). They had noted that their solution of the model was not particularly sensitive to variation of the exchange of $20 \alpha$-diHP between pools 3 and 4. The present unconstrained estimation of parameters indicates that the interchange of $20 \alpha$-diHP $\left(\mathbf{k}_{34}\right.$ and $\left.\mathbf{k}_{43}\right)$ is more rapid than the exchange of progesterone $\left(\mathbf{k}_{21}\right.$ and $\left.\mathbf{k}_{12}\right)$. It had been assumed by Paterson et al. (1976) that splanchnic extraction $\left(\mathrm{k}_{04}\right)$ of $20 \alpha$-diHP accounted for $35 \%$ of its metabolism, and we have now estimated that this accounts for $78 \%$ of $20 \alpha$-diHP removal. The latter value is about double that of progesterone, and the results imply $20 \alpha$-diHP removal by some source other than the splanchnic organs.

In the analysis of tracer kinetic data it is a common practice to divide the pool sizes for a substance by its measured concentration in blood, and so express the pools as volumes of distribution. Paterson et al. (1976) determined that progesterone and $20 \alpha$-diHP pools were equivalent to 8 and 70 litres blood steroid, respectively, and since the mean body weight of their sheep was $41 \mathrm{~kg}$, it was concluded that both steroids must attain tissue concentrations considerably 
greater than blood concentration. This could be achieved by binding to intracellular receptors, and through the high lipid solubility of progesterone. It is an assumption in tracer kinetic analysis that each pool has characteristic kinetic behaviour and in consequence each pool has a uniform specific activity. This cannot be strictly true for the large pools of progesterone and $20 \alpha-\mathrm{diHP}$, and any estimated parameters of distribution must then be approximate.

The assumption by Paterson et al. (1976) that the two steroids occupied the same volume of distribution has not been confirmed. Apparent pool volumes of progesterone are 10 and 69 litres (in terms of blood steroid) while the $20 \alpha$-dihydroprogesterone volumes are 5.6 and 73 litres. The probable inhomogeneity of the larger pools, discussed above, may make the apparent difference insignificant but this is unlikely to be so for the smaller pools. It seems likely that some tissues in rapid equilibrium with blood steroid contain much greater quantities of progesterone than of $20 \alpha-$ dihydroprogesterone, and that an organ(s) with high blood flow (e.g. gravid uterus) is the site of rapid conversion of progesterone to $20 \alpha$-dihydroprogesterone.

We thank the late Miss Grace Needham and Miss Maureen Hamon for skilled technical assistance.

\section{References}

Ainsworth, L. \& Ryan, K.J. (1967) Steroid hormone transformation by endocrine organs from pregnant mammals. II. Formation and metabolism of progesterone by bovine and sheep placental preparations in vitro. Endocrinology 81, 1349-1356.

Bedford, C.A., Harrison, F.A. \& Heap, R.B. (1972) The metabolic clearance rate and production rate of progesterone and the conversion of progesterone to $20 \alpha$-hydroxypregn-4-en-3-one in the sheep. J. Endocr. 55, 105-118.

Bedford, C.A., Harrison, F.A. \& Heap, R.B. (1974) The splanchnic, uterine, ovarian and adrenal uptake of progesterone and 20x-dihydroprogesterone in the pregnant and non-pregnant sheep. $J$. Endocr. 62, $277-290$.

Elsner, C.W., Magyar, D.M., Fridshal, D., Eliot, J., Klein, A., Glatz, T., Nathanielsz, P.W. \& Buster, J.E. (1980) Time-trend analysis of plasma C-21 steroids in fetal and maternal sheep during the last 18 days of gestation. Endocrinology 107, 801-808.

Heap, R.B., Gwyn, M., Laing, J.A. \& Walters, D.E.
(1973) Pregnancy diagnosis in cows; changes in milk progesterone concentration during the oestrous cycle and pregnancy measured by a rapid radioimmunoassay. J. agric. Sci., Camb. 81, 151-157.

Paterson, J.Y.F., Bedford, C.A., Harrison, F.A. \& Heap, R.B. (1976) Progesterone and 20 $\alpha$-dihydroprogesterone in sheep: a model of their distribution and metabolism. $J$. Reprod. Fert. 46, 313-322.

Pierrepoint, C.G., Anderson, A.B.M., Tumbull, A.C. \& Griffiths, K. (1973) In vivo and in vitro studies of steroid metabolism by the sheep placenta. In The Endocrinology of Pregnancy and Parturition: Experimental Studies in the Sheep, pp. 40-63. Ed. C. G. Pierrepoint. Alpha Omega Alpha, Cardiff.

Ricketts, A.P. \& Flint, A.P.F. (1980) Onset of synthesis of progesterone by ovine placenta. J. Endocr. 86, 337347.

Short, R.V. \& Moore, N.W. (1959) Progesterone in blood. V. Progesterone and 20 $\alpha$-hydroxypregn-4-en3 -one in the placenta and blood of ewes. J. Endocr. 19, 288-293.

Received 7 December 1982 